JSPS Grants-in-Aid for Scientific Research (S)

Understanding Persistent Deflation in Japan

Working Paper Series

No. 092

March 2017

\title{
The Effectiveness of Consumption Taxes and Transfers as Insurance against Idiosyncratic Risk
}

\author{
Tomoyuki Nakajima \\ Shuhei Takahashi
}

\author{
UTokyo Price Project \\ 702 Faculty of Economics, The University of Tokyo, \\ 7-3-1 Hongo, Bunkyo-ku, Tokyo 113-0033, Japan \\ Tel: +81-3-5841-5595 \\ E-mail: watlab@e.u-tokyo.ac.jp \\ http://www.price.e.u-tokyo.ac.jp/english/
}




\title{
The Effectiveness of Consumption Taxes and Transfers
}

\section{as Insurance against Idiosyncratic Risk*}

\author{
Tomoyuki Nakajima ${ }^{\dagger}$ and Shuhei Takahashi ${ }^{\ddagger}$
}

January 26, 2017

\begin{abstract}
We quantitatively evaluate the effectiveness of a consumption tax and transfer program as insurance against idiosyncratic earnings risk. Our framework is a heterogeneousagent, incomplete-market model with idiosyncratic wage risk and indivisible labor. The model is calibrated to the U.S. economy. We find a weak insurance effect of the transfer program. Extending the transfer system from the current scale raises consumption uncertainty, which increases aggregate savings and reduces the interest rate. Furthermore, consumption inequality shows a small decrease.

Keywords: Consumption taxes; Transfers; Risk sharing; Consumption inequality; Indivisible labor; Incomplete markets

JEL classification: E62, D31, J22, C68
\end{abstract}

*This paper was previously circulated as "Consumption Taxes and Divisibility of Labor under Incomplete Markets." We thank Ken Yamada and Shenghao Zhu for their helpful comments. We also thank seminar and conference participants at the AEI Joint Workshop 2016, Midwest Macroeconomics Meetings 2016 Spring, Taipei International Conference on Growth, Trade, and Dynamics 2016, Society for Economic Dynamics Annual Meeting 2016, Asian Meeting of the Econometric Society 2016, and National University of Singapore for their helpful comments. Nakajima gratefully acknowledges the financial support from Grant-in-Aid for Scientific Research (S) 24223003 and (A) 15H01939. Takahashi gratefully acknowledges the financial support from Grant-in-Aid for Scientific Research (A) 16H02026 and Grant-in-Aid for Young Researchers (B) 26780119. Any remaining errors are our own.

${ }^{\dagger}$ Professor, Institute of Economic Research, Kyoto University, Yoshida-Honmachi, Sakyo-ku, Kyoto 6068501, Japan, and Senior Research Fellow, Canon Institute for Global Studies.

${ }^{\ddagger}$ Assistant Professor, Institute of Economic Research, Kyoto University, Yoshida-Honmachi, Sakyo-ku, Kyoto 606-8501, Japan. 


\section{Introduction}

Households face substantial idiosyncratic labor income risk, and private insurance against such risk is far from perfect. The presence of uninsurable idiosyncratic earnings risk implies a potential role of government policies. The present paper examines the effectiveness of a consumption tax and transfer system as insurance against idiosyncratic earnings risk in an Aiyagari (1994)-style model with endogenous labor supply. We find that the transfer program is ineffective in terms of risk sharing. Expanding the current transfer scheme in the United States increases consumption volatility and precautionary savings. Thus, aggregate savings increase and the interest rate falls.

Previous studies, such as Flodén (2001), Flodén and Lindé (2001), and Alonso-Ortiz and Rogerson (2010), show that a transfer system based on labor income taxes effectively reduces consumption uncertainty, leading to lower aggregate savings and a higher interest rate. However, transfer schemes based on consumption and labor income taxes would have different implications as insurance because they generate different distributions of tax burdens across states. Although there have been discussions on increasing consumption taxes in several countries, the insurance effect of a consumption tax and transfer program is not fully understood. ${ }^{1}$

Following Alonso-Ortiz and Rogerson (2010), we analyze a tax and transfer system using a heterogeneous-agent, incomplete-market model with indivisible labor (e.g., Chang and Kim (2006, 2007) and Krusell, Mukoyama, Rogerson, and Şahin (2010, 2011)). The indivisibility of labor is an important characteristic of individual labor supply. ${ }^{2}$ It is also a natural starting point in analyzing government insurance and redistribution programs because, as emphasized by Saez (2002), empirical studies reveal that the extensive margin of labor supply responses is significant for low-income households, which are likely to be affected the most by such a

\footnotetext{
${ }^{1}$ For example, the consumption tax rate increased in Japan from 5\% to 8\% in April 2014 and will rise again in October 2019 to 10\%. We analyze the Japanese economy in Appendix B.

${ }^{2}$ Indivisible labor is often rationalized by the 1) coordination among workers within firms (Alonso-Ortiz and Rogerson (2010)) and 2) fixed costs of working outside home (Hansen (1985) and Cho and Rogerson (1988)).
} 
policy. Furthermore, this class of models accounts well for the inequalities in wealth and earnings data and therefore is suitable for quantitative analyses.

Specifically, the model includes a large number of infinitely-lived households. ${ }^{3}$ Households differ in terms of their labor productivity, and their wage is equal to the marginal product of their labor. Idiosyncratic productivity is stochastic and generates idiosyncratic wage risk. Asset markets are incomplete. There are only two risk-free assets: government bonds and physical capital. Hence, households cannot fully insure against idiosyncratic wage risk, and they partially self-insure using savings. Labor supply is endogenous. Households choose to work full time or not to work at all. Furthermore, a representative firm operates with the neoclassical production function.

We analyze changes in a consumption tax and transfer program in an environment where the government finances lump-sum transfers to households and exogenous government consumption through taxes on consumption, capital income, and labor income, as well as using government bonds. Aiyagari and McGrattan (1998) and Flodén (2001) find that these factor income taxes and government debt improve risk sharing. Thus, we include, but fix them, changing the consumption tax rate and adjusting transfers endogenously such that the government budget constraint holds. This allows us to quantify the insurance effect of consumption taxes and transfers when other policy tools also provide some degree of risk sharing. We calibrate the model to the U.S. economy and focus on a stationary equilibrium.

We find a weak insurance effect of the consumption tax and transfer program. More specifically, expanding the program from its current scale initially worsens risk sharing. The key to this result is indivisible labor, which implies that households adjust their labor supply through the extensive margin. Under the current levels of taxes and transfers, wealth

\footnotetext{
${ }^{3}$ The use of an infinitely-lived household model allows a direct comparison between our results and those of Flodén (2001), Flodén and Lindé (2001), and Alonso-Ortiz and Rogerson (2010), who also analyze a simple tax and transfer system. Furthermore, as Aiyagari and McGrattan (1998) emphasize, most of the parameters can be set as in the baseline neoclassical growth model with a representative agent, and the process for idiosyncratic productivity can be calibrated to micro-level data. A disadvantage is that it is not possible to analyze the life-cycle implications and intergenerational redistribution or risk sharing. We leave these issues to future research.
} 
poor households choose employment in almost all states. As transfers increase, the income effect causes those households to reduce employment. They do so in states with low productivity, living on transfers and enjoying increased leisure. In contrast, in states with high productivity, they remain employed and work for the same number of hours as before. Importantly, the after-tax wage rate (relative to output) increases here because the aggregate labor supply decreases and the labor income tax rate remains unchanged. Hence, with the aforementioned employment responses, the variation in labor income across states increases substantially. When the level of transfers is low, consumption uncertainty rises as well, increasing precautionary savings. Hence, aggregate savings increase and the interest rate falls. The reduction in consumption inequality is also moderate because labor income inequality widens substantially and even with larger lump-sum transfers, total income inequality shows a small decrease.

In the present model, the transfer system based on labor income taxes provides better insurance against idiosyncratic wage risk. Although an increase in transfers generates similar employment responses to those in the program based on consumption taxes, an increase in the labor income tax rate decreases the after-tax wage rate. Hence, the variation in labor income across contingencies increases only mildly. With larger transfers, which are independent of states, the uncertainty in total income decreases. Hence, aggregate savings decrease, while the interest rate rises. This result is the same as that of Alonso-Ortiz and Rogerson (2010).

Furthermore, the transfer scheme based on consumption taxes is much more effective for risk sharing and reducing inequality if labor is divisible, that is, if households adjust their labor supply through the intensive margin. We solve the divisible labor version of our model, which is similar to that of Aiyagari and McGrattan (1998), Flodén (2001), Flodén and Lindé (2001), and Pijoan-Mas (2006). As consumption taxes and transfers increase, households reduce their labor hours (largely) uniformly in all states. With larger lump-sum transfers, the uncertainty in total resources decreases substantially, reducing precautionary savings. Hence, extending the tax and transfer program leads to lower aggregate savings and a higher 
interest rate. The reduction in consumption inequality is also substantial.

Lastly, we examine the welfare implications of the consumption tax and transfer program. Following Flodén (2001), we decompose the utilitarian welfare gain from expanding the transfer scheme into the gains from changing uncertainty, inequality, and the level (efficiency). We find that under indivisible labor, the sum of the uncertainty and inequality gains is negative, although a further decomposition between the two needs an additional assumption. The level gain is positive. The trade-off is the opposite to that revealed by existing studies: A more generous transfer system generates welfare gains by reducing uncertainty and inequality, but produces a welfare loss by lowering efficiency (e.g., Flodén (2001)). In contrast, the results under divisible labor are in line with the conventional wisdom. These findings confirm our results that the consumption tax and transfer system is not effective in providing insurance and reducing inequality under indivisible labor and that the flexibility in the labor supply improves its effectiveness substantially.

The nature of labor supply responses is also important when designing a tax and transfer system. For example, Saez (2002) shows that the optimal income transfer program for lowincome individuals, especially the optimal marginal tax rate, depends crucially on whether individuals adjust their labor supply through the intensive or the extensive margins. Our analysis complements the work of Saez (2002) and related studies. On the one hand, these prior studies consider tax and transfer programs that are more flexible than ours are. On the other hand, while Saez (2002) and others use a static model with no uncertainty, we use the neoclassical growth model with uninsured idiosyncratic wage risk. The dynamic model allows us to analyze how a tax and transfer system influences capital accumulation, wealth inequality, and risk sharing. We find that those effects also depend crucially on whether labor supply responses occur along the intensive or extensive margins. To the best of our knowledge, this is a new result.

This study also contributes to the literature on the macroeconomic effects of increas- 
ing consumption taxes in the presence of heterogeneity and incomplete markets. ${ }^{4}$ Ventura (1999), Nishiyama and Smetters (2005), Kitao (2011), and others analyze the aggregate implications of replacing progressive income taxes with flat consumption taxes, including its effect on consumption uncertainty and inequality, in an overlapping generations model with life cycles and uninsurable idiosyncratic wage risk. Kitao (2011) also examines the effect of increasing consumption taxes and transfers, finding that the policy reduces aggregate savings and increases the interest rate. These models assume divisible labor and thus our finding under divisible labor is consistent with that of Kitao (2011). Correia (2010) uses an infinitely-lived, heterogeneous-agent model to analyze the effects of consumption taxes and transfers on inequality. The model is deterministic and hence the paper does not analyze the insurance effect. The present study is the first to quantify the effect of the consumption tax and transfer scheme on risk sharing in an infinitely-lived, heterogeneous-agent model.

The remainder of the paper proceeds as follows. Section 2 presents the model, while Section 3 explains the parameter values. Section 4 presents the main results, and Section 5 conducts robustness checks. Section 6 concludes the paper. In the appendix, we examine a transfer program based on labor income taxes for the United States and analyze a consumption tax and transfer scheme for Japan. The numerical method is also explained in the appendix.

\section{Model}

Our model is a neoclassical growth model, with uninsured idiosyncratic wage risk and indivisible labor, similar to the models of Chang and Kim (2007), Alonso-Ortiz and Rogerson (2010), and Krusell, Mukoyama, Rogerson, and Şahin (2010, 2011). We explain the model in the order of firms, households, and the government.

\footnotetext{
${ }^{4}$ In a deterministic model with identical households and perfect financial markets, Coleman (2000) finds that increasing consumption taxes and reducing capital and labor income taxes greatly improve welfare in the United States.
} 


\subsection{Firms}

A representative firm rents capital $K$ and labor $N$ from households and produces good $Y$. The production function is

$$
Y=K^{\theta}(z N)^{1-\theta},
$$

where $z$ denotes labor-augmenting productivity and $\theta \in(0,1)$ is the capital share. Productivity grows exogenously at a constant rate of $g$, that is, $z^{\prime}=(1+g) z$. Note that a prime denotes a next-period value hereinafter.

The firm maximizes its static profit, taking the rental rate of capital $r$ and the wage rate $w$ as given. The first-order conditions are

$$
r=\theta z^{1-\theta} K^{\theta-1} N^{1-\theta}-\delta
$$

and

$$
w=(1-\theta) z^{1-\theta} K^{\theta} N^{-\theta},
$$

where $\delta \in(0,1)$ is the capital depreciation rate. Since the economy grows, it is convenient to divide (some) variables by output and to analyze a stationary equilibrium. The profitmaximizing conditions (2) and (3) are written as:

$$
r=\frac{\theta}{\tilde{K}}-\delta
$$

and

$$
\tilde{w}=\frac{(1-\theta)}{N},
$$

where $\tilde{K}=K / Y$ and $\tilde{w}=w / Y$. 


\subsection{Households}

There is a continuum of households (measure one). Households are endowed with one unit of time in each period. Following Chang and Kim (2007), the momentary utility function is

$$
u(c, h)=\ln c-\psi h^{1+\frac{1}{\varphi}}
$$

where $c$ is consumption, $h$ is hours worked, $\psi$ adjusts the disutility of labor, and $\varphi$ is the Frisch labor supply elasticity. Labor is indivisible, as in Hansen (1985) and Rogerson (1988). Households choose to work for fixed hours or not to work at all: $h \in\{0, \bar{h}\}$.

Households differ in their labor productivity $e$. Idiosyncratic productivity is mutually independent and follows a discrete Markov chain. This is the source of idiosyncratic wage risk.

Households cannot fully insure against idiosyncratic wage risk because asset markets are incomplete. There are two assets in the economy: physical capital and government bonds. Since there is no aggregate uncertainty, these two assets are perfect substitutes for households and both assets earn the (risk-free) interest rate $r$. At the beginning of each period, households are distinguished by their current productivity $e$ and total wealth $a$. There is a borrowing constraint: $a \geq 0$.

Define $\tilde{a}=a / Y$. Let $V(\tilde{a}, e)$ be the beginning-of-period value function, which satisfies

$$
V(\tilde{a}, e)=\max \left\{V^{E}(\tilde{a}, e), V^{N}(\tilde{a}, e)\right\}
$$

where $V^{E}(\tilde{a}, e)$ is the value function when households choose employment in the current period, and $V^{N}(\tilde{a}, e)$ is the value function when they choose non-employment. Solving the consumption-saving problem, conditional on the employment choice, determines $V^{E}(\tilde{a}, e)$ and $V^{N}(\tilde{a}, e)$ as: 


$$
\begin{gathered}
V^{E}(\tilde{a}, e)=\max _{\left\{\tilde{c}, \tilde{a}^{\prime}\right\}}\left\{u(\tilde{c}, \bar{h})+\beta E\left[V\left(\tilde{a}^{\prime}, e^{\prime}\right) \mid e\right]\right\} \\
\text { subject to }\left(1+\tau_{c}\right) \tilde{c}+(1+g) \tilde{a}^{\prime} \leq\left[1+\left(1-\tau_{k}\right) r\right] \tilde{a}+\left(1-\tau_{n}\right) \tilde{w} e \bar{h}+\tilde{T} \\
\tilde{c} \geq 0, \tilde{a}^{\prime} \geq 0,
\end{gathered}
$$

and

$$
\begin{gathered}
V^{N}(\tilde{a}, e)=\max _{\left\{\tilde{c}, \tilde{a}^{\prime}\right\}}\left\{u(\tilde{c}, 0)+\beta E\left[V\left(\tilde{a}^{\prime}, e^{\prime}\right) \mid e\right]\right\} \\
\text { subject to }\left(1+\tau_{c}\right) \tilde{c}+(1+g) \tilde{a}^{\prime} \leq\left[1+\left(1-\tau_{k}\right) r\right] \tilde{a}+\tilde{T} \\
\tilde{c} \geq 0, \tilde{a}^{\prime} \geq 0,
\end{gathered}
$$

where $\tilde{c}=c / Y, \beta \in(0,1)$ is the discount factor, and $E$ is the conditional expectation. In the budget constraint, $\tau_{c}, \tau_{k}$, and $\tau_{n}$ denote the consumption, capital income, and labor income tax rates, respectively, and $\tilde{T}=T / Y$, where $T$ represents the lump-sum transfers from the government to households. ${ }^{5}$

\subsection{Government}

The government finances its consumption and lump-sum transfers to households through taxes, debt, and net imports. ${ }^{6}$ The government budget constraint is

$$
G+T+r B=B^{\prime}-B+\tau_{n} w N+\tau_{k} r(K+B)+\tau_{c} C-M,
$$

\footnotetext{
${ }^{5}$ The next-period asset $\tilde{a}^{\prime}$ is multiplied by $(1+g)$. The original budget constraint is divided by $Y$ and $a^{\prime} / Y=\left(Y^{\prime} / Y\right)\left(a^{\prime} / Y^{\prime}\right)=(1+g) \tilde{a}^{\prime}$.

${ }^{6}$ We include net imports following Trabandt and Uhlig (2011), from which most of the parameter values are taken. However, the ratio of net imports to GDP is relatively low in the United States. See the next section for more details. Hence, excluding net imports, as in Aiyagari and McGrattan (1998) and Flodén (2001), does not change the main conclusion of this study.
} 
where $G$ is government consumption, $B$ is government debt, $C$ is aggregate consumption, and $M$ is net imports. Dividing (10) by $Y$ leads to the following constraint:

$$
\tilde{G}+\tilde{T}+r \tilde{B}=(1+g) \tilde{B}^{\prime}-\tilde{B}+\tau_{n} \tilde{w} N+\tau_{k} r(\tilde{K}+\tilde{B})+\tau_{c} \tilde{C}-\tilde{M}
$$

where $\tilde{G}=G / Y, \tilde{B}=B / Y, \tilde{C}=C / Y$, and $\tilde{M}=M / Y$. In the stationary equilibrium, $\tilde{B}=\tilde{B}^{\prime}$

\subsection{Recursive Equilibrium}

Let $\Gamma(\tilde{a}, e)$ be the stationary distribution of households over wealth and idiosyncratic productivity. Given the government policy $\left(\tilde{G}, \tilde{B}, \tilde{M}, \tau_{c}, \tau_{k}, \tau_{n}\right)$, a stationary competitive equilibrium is $\left(\tilde{w}, r, V, V^{E}, V^{N}, \tilde{c}, \tilde{a}^{\prime}, h, \tilde{K}, N, \tilde{C}, \tilde{T}, \Gamma\right)$ that satisfies the following conditions:

1. Households' optimization:

$V(\tilde{a}, e), V^{E}(\tilde{a}, e)$, and $V^{N}(\tilde{a}, e)$ satisfy $(7),(8)$, and (9), respectively, while $\tilde{c}(\tilde{a}, e), \tilde{a}^{\prime}(\tilde{a}, e)$, and $h(\tilde{a}, e)$ are the associated policy functions.

2. Firms' optimization:

The representative firm chooses $\tilde{K}$ and $N$ to satisfy (4) and (5).

3. Labor market clearing:

$$
N=\int x h(\tilde{a}, e) d \Gamma
$$

4. Asset market clearing:

$$
\tilde{K}^{\prime}+\tilde{B}^{\prime}=\int \tilde{a}^{\prime}(\tilde{a}, e) d \Gamma
$$

5. Government budget constraint:

The government budget constraint holds, as in (11), with $\tilde{C}=\int \tilde{c}(\tilde{a}, e) d \Gamma$. 


\section{Stationary household distribution:}

Household decisions and the transition probabilities of $e$ govern the evolution of the household distribution. Specifically, for all $D \subseteq S$, $\Gamma\left(D, e^{\prime}\right)=\int_{\left\{(\tilde{a}, e) \mid \tilde{a}^{\prime}(\tilde{a}, e) \in D\right\}} \pi_{e}\left(e^{\prime} \mid e\right) d \Gamma$, where $\pi_{e}\left(e^{\prime} \mid e\right)$ is the transition probability from $e$ to $e^{\prime}$.

Lastly, output $Y$ is computed using (1) as $Y=\tilde{K}^{\frac{\theta}{1-\theta}} z N$. Hence, the government policy affects the level of output by changing $\tilde{K}$ and $N$, but does not change the growth rate of output, which is constant at $g$.

\section{Benchmark Parameter Values}

We calibrate the above model to the U.S. economy. Table 1 lists the benchmark parameter values. One period corresponds to one year.

The parameter values are taken primarily from Trabandt and Uhlig (2011). The growth rate of real GDP $g$ is 0.02 per year. The capital depreciation rate $\delta$ is 0.07 and the capital share $\theta$ is 0.38 .

Households work for one-third of their time endowment, when employed: $\bar{h}=0.333$. This is the standard assumption made in previous studies, such as Chang and $\operatorname{Kim}(2006,2007)$. The Frisch elasticity of labor supply $\varphi$ is 1.0 and the disutility parameter $\psi$ is adjusted so that the total hours worked $H=\int h(\tilde{a}, e) d \Gamma$ is 0.25 , following Trabandt and Uhlig (2011). ${ }^{7}$

Idiosyncratic productivity $e$ follows a 17 -state Markov chain. The Markov chain is obtained by approximating an $\mathrm{AR}(1)$ process, $\ln e^{\prime}=\rho \ln e+\varepsilon^{\prime}, \varepsilon^{\prime} \sim N\left(\mu_{\varepsilon}, \sigma_{\varepsilon}^{2}\right)$, using the method of Tauchen (1986). We set $\rho=0.94$ and $\sigma_{\varepsilon}=0.205$, following Alonso-Ortiz and Rogerson (2010). ${ }^{8}$ As Alonso-Ortiz and Rogerson (2010) argue, these values are in line with

\footnotetext{
${ }^{7}$ Since labor is indivisible, what matters is the disutility of employment, or $\psi \bar{h}^{1+\frac{1}{\varphi}}$. Hence, varying $(\psi, \varphi)$ does not affect the equilibrium if $\psi \bar{h}^{1+\frac{1}{\varphi}}$ is kept unchanged. The distinction between $\psi$ and $\varphi$ matters for the welfare analysis.

${ }^{8}$ We adjust $\mu_{\varepsilon}$ so that the mean of $e$ is 1.0, as in Aiyagari and McGrattan (1998).
} 
existing estimates.

With respect to the government policy, the benchmark consumption tax rate $\tau_{c}$ is 0.05 . The labor income tax rate $\tau_{n}$ is 0.28 , while the capital income tax rate $\tau_{k}$ is 0.36 . The share of government consumption in GDP $\tilde{G}$ is 0.18 . The ratio of net imports to GDP $\tilde{M}$ is 0.04 . The ratio of government debt to GDP $\tilde{B}$ is 0.63 .

Lastly, we choose the discount factor $\beta$ so that the after-tax rate of the return on savings $\left(1-\tau_{k}\right) r$ is $4.0 \%$, at the benchmark parameter values, following Trabandt and Uhlig (2011). The result is $\beta=0.9696$.

\section{Results}

We change the consumption tax rate from $0 \%$ to $90 \%$ in $5 \%$ increments and adjust the transfer-output ratio endogenously such that the government budget constraint (11) holds. ${ }^{9}$ In contrast, we fix the ratios of government consumption, bonds, and net imports to output at their benchmark values, following Aiyagari and McGrattan (1998) and Flodén (2001). ${ }^{10}$ As shown in Figure 1, the transfer-output ratio increases monotonically. ${ }^{11}$

In order to understand the effect of the tax and transfer program on risk sharing, we start by examining their effects on the interest rate and the capital-output ratio. Since the debt-output ratio is constant, the movement of the capital-output ratio tracks the movement of aggregate savings. In our environment, households face uninsurable idiosyncratic income risk and engage in precautionary savings. If a larger tax and transfer scheme provides better insurance, then it would cause aggregate savings to decrease and the interest rate to rise.

Figure 2 shows that the opposite is true and that expanding the tax and transfer system

\footnotetext{
${ }^{9}$ The method used in this solution is similar to that used by Aiyagari and McGrattan (1998), Flodén (2001), Flodén and Lindé (2001), and Alonso-Ortiz and Rogerson (2010). The detail of the method is explained in Appendix C.

${ }^{10}$ Our main conclusion does not change when we fix the amounts (not the ratios to output) of the government consumption, government bonds, and net imports to those under the initial tax rate $\left(\tau_{c}=0.05\right.$ in our case), as in Trabandt and Uhlig (2011). See the next section for more details.

${ }^{11}$ There is no peak in the consumption Laffer curve. In addition to the transfer-output ratio, the amount of transfers increases monotonically as well. The same result holds when labor is divisible, as shown later and by Feve, Matheron, and Sahuc (2013).
} 
from the current U.S. level actually worsens risk sharing. For example, consider an increase in the consumption tax rate from $5 \%$ to $35 \%$. This corresponds to raising the tax rate from the U.S. rate to the rate in Denmark (Trabandt and Uhlig (2011)). The increase in the tax rate increases the transfer-output ratio enormously from 0.116 to 0.289 . In spite of the large increase in transfers, the interest rate falls from $4.0 \%$ to $3.9 \%$, while the capital-output ratio increases from 2.87 to 2.90 .

The degree of risk sharing can also be inferred from the dispersion of consumption across states. One measure is the Gini coefficient for consumption, although this also reflects consumption inequality across households. The upper-right panel of Figure 3 shows that an extension of the transfer scheme leads to a small change in consumption uncertainty. ${ }^{12}$ When the tax rate is raised from $5 \%$ to $35 \%$, the Gini actually increases slightly from 0.238 to 0.241 .

These results are counter-intuitive and contrast with those of the transfer system based on labor income taxes, as shown in Flodén (2001), Flodén and Lindé (2001), and Alonso-Ortiz and Rogerson (2010).

Labor supply adjustments should be responsible for the results. If labor supply is fixed exogenously and is invariant to the scale of the tax and transfer program, then a more generous program would surely make resources across states more equal, improving risk sharing. Hence, we next examine changes in labor supply. As shown in Figure 4, aggregate labor hours, measured in both raw and efficiency units, decrease with the consumption tax rate. The reduction in aggregate labor input raises the wage rate (relative to output), as implied by (5). Since the labor income tax rate is constant, the after-tax wage rate increases.

An important feature of the present model is that indivisible labor causes the reduction in labor hours to vary substantially across states. In states with low productivity, households switch from employment to non-employment, live on transfers, and enjoy increased leisure.

\footnotetext{
${ }^{12}$ A similar pattern is observed for other measures on uncertainty and inequality, such as the standard deviation of the log of consumption. We use the Gini coefficient throughout the paper as a measure of the dispersion across states and the inequality across households. Labor earnings and wealth can be zero and hence we cannot apply the log transformation.
} 
In contrast, in states with high productivity, households remain employed and work for the same number of hours as before. ${ }^{13}$ With these employment changes and the increased wage rate, the variation in labor income across states increases substantially, as shown by the movement of the labor income Gini in Figure 3. When the level of transfers is low, consumption uncertainty also increases, especially for low-wealth households, increasing their incentive to save for self-insurance purposes. This is evidenced by the result in Figure 5, which shows that the number of low-wealth households decreases initially as the consumption tax rate increases.

Furthermore, since the number of low-wealth households decreases and wealth-rich households decrease their savings in response to a lower interest rate, the wealth Gini decreases as the tax and transfer program is extended. Since labor income inequality increases substantially, even with larger transfers, total income inequality remains essentially unchanged. Hence, consumption inequality is largely unchanged.

The tax and transfer system is much more effective in providing insurance and reducing inequality under divisible labor. We resolve our model, allowing households to choose any level of labor hours below their time endowment. We maintain the same parameter values as those in the indivisible labor case, except for the discount factor and the disutility of labor, which are adjusted to match the same targets as the indivisible labor model. ${ }^{14}$ Note that the results for the divisible labor case are also presented in Figures 1-5. The flexibility of labor supply has little influence on the transfer-output ratio. However, it substantially improves the ability of the transfer program in improving risk sharing. When labor is divisible, an extension of the transfer system causes the capital-output ratio to decrease and the interest rate to increase. The consumption Gini also decreases.

\footnotetext{
${ }^{13}$ These employment responses can be inferred by comparing the movements of raw and efficiency-weighted hours. Efficiency-weighted labor decreases far less substantially than hours worked in raw units do. This implies that households reduce their employment in states with low productivity by more than they do in states with high productivity. Alonso-Ortiz and Rogerson (2010) show that a similar result holds when labor income taxes and transfers increase and the composition effect is responsible for cross-country differences in labor productivity.

${ }^{14}$ Specifically, we set $\beta=0.9711$ and $\psi=4.80$.
} 
Under divisible labor, households reduce their labor hours (largely) uniformly in all contingencies. Accordingly, with larger transfers, which are independent of states, households face less volatile total income and consumption, reducing their incentive to save for selfinsurance. Hence, aggregate savings decrease as consumption-tax financed transfers increase, leading to a higher interest rate and a lower capital-output ratio. This is also evidenced by the result in Figure 4, which shows that the number of low-wealth households increases monotonically with the consumption tax rate. The wealth Gini increases with the consumption tax rate because the number of low-wealth households increases and the higher interest rate increases the savings of wealth-rich households. Consumption inequality across households is reduced substantially because labor income inequality increases modestly and with larger transfers, the inequality in the total income substantially decreases.

Next, we explore the welfare implication of extending the consumption tax and transfer program. Our welfare measure is utilitarian, as in the most related studies. We then use the method of Flodén (2001) to decompose the welfare gain of an extension of the transfer program into gains arising from changes in the level (efficiency), uncertainty, and inequality. The utilitarian welfare under a certain scale of the program is given by

$$
U=\frac{\ln Y_{0}}{1-\beta}+\frac{\beta \ln (1+g)}{(1-\beta)^{2}}+\iint V(\tilde{a}, e) d \Gamma(\tilde{a}, e),
$$

where $Y_{0}$ is the level of output at the initial level of productivity ( $z_{0}=1.0$ for normalization). The first term captures the level of output or consumption. The second term is policy invariant and merely adjusts the exogenous growth. The third term is the utilitarian welfare for the stationary equilibrium computed above.

Consider a change in the scale of the tax and transfer program, changing the consumption tax rate from the initial rate of $5 \%$ to a new rate. Let $\omega_{U}$ be the utilitarian welfare gain of the policy change. The welfare gain is expressed as a fraction of consumption at the initial tax rate. Specifically, the number shows by how much consumption at the initial tax rate 
must increase at all states and dates in order to achieve the utilitarian welfare attained at the new tax rate. Given the utility function,

$$
\omega_{U}=\exp \left[\beta\left(U_{n e w}-U_{\text {initial }}\right)\right]-1
$$

where $U_{\text {new }}$ and $U_{\text {initial }}$ are the utilitarian welfare measures under the new and initial tax rates, respectively.

As shown in Flodén (2001), $\omega_{U}$ is decomposed as follows:

$$
\omega_{U}=\left(1+\omega_{l e v}\right)\left(1+\omega_{u n c}\right)\left(1+\omega_{\text {ine }}\right)-1
$$

where $\omega_{l e v}$ is the level gain, $\omega_{u n c}$ is the uncertainty gain, and $\omega_{\text {ine }}$ is the inequality gain. The level gain $\omega_{l e v}$ captures the welfare gain arising from a change in the level of aggregate consumption (i.e., a change in aggregate leisure is compensated), assuming no uncertainty and no inequality (in a representative household). The uncertainty gain $\omega_{\text {unc }}$ is the gain in the uncertainty cost, which is computed as the welfare difference between having the average consumption and leisure and having the average certainty-equivalent consumption and leisure. The inequality gain $\omega_{\text {ine }}$ is the difference in the cost of inequality, which is computed as the difference between the welfare of having the average certainty-equivalent consumption and leisure and the average welfare of having certainty-equivalent consumption and leisure. Since a pair of certainty-equivalent consumption and leisure is not unique, we follow Flodén (2001) in fixing the certainty-equivalent leisure in two ways: setting labor hours to the optimal choice in the current period $(h=h o p t)$ and setting it to the economy average $(h=H)$. As shown below, the choice only affects the decomposition between the inequality and uncertainty gains, keeping the sum of the two and the level gain unchanged.

Figure 6 shows the result for the indivisible labor economy. The welfare decomposition confirms our earlier results. When labor is indivisible, increasing consumption taxes initially worsens uncertainty and inequality. In contrast, the level improves. For example, when the 
consumption tax rate is raised from $5 \%$ to $35 \%$, the level gain is $1.4 \%$, while the sum of the uncertainty and inequality gains is $-2.7 \%$. These results are the opposite to those in the usual trade-off for a transfer program, that is, insurance and equity versus inefficiency. The positive level gain arises in the present setup for the following reason. As transfers increase, less productive households stop working, and hence the average productivity of employed households increases. This allows households to enjoy a large increase in leisure with a relatively small decrease in consumption, thus improving efficiency. The worsening uncertainty and inequality are consistent with the earlier result. The decomposition into the inequality and uncertainty gains depends on how we determine the certainty-equivalent leisure. When we use $h=$ hopt, the inequality gain is $-4.1 \%$ and the uncertainty gain is $1.4 \%$. When we use $h=H$, the inequality gain is $1.4 \%$ and the uncertainty gain is $-4.1 \%$. Hence, the signs of the gains differ between $h=h o p t$ and $h=H$. However, the sum of the uncertainty and inequality gains remains unchanged and is still negative, even when the consumption tax rate reaches $90 \%$. Indeed, reducing the tax rate from the current level improves the sum of the inequality and uncertainty gains.

As shown in Figure 7, the welfare implication for the divisible labor economy is also in line with our earlier results. Under divisible labor, expanding the tax and transfer system improves uncertainty and inequality in terms of welfare. For example, when the consumption tax rate is raised from $5 \%$ to $35 \%$, the sum of the inequality and uncertainty gains is $2.7 \%$. Furthermore, the extension of the program improves both uncertainty and inequality. When we use $h=h o p t$, the inequality gain is $1.7 \%$ and the uncertainty gain is $1.0 \%$. When we use $h=H$, the inequality gain is $1.5 \%$ and the uncertainty gain is $1.2 \%$. In contrast, the level cost is $3.7 \%$. The composition effect is much weaker here than it is in the indivisible labor case. Hence, a more generous transfer system decreases average consumption substantially and reduces welfare in terms of the level, even when an increase in leisure is taken into account.

The analysis in this section suggests that the consumption tax and transfer program is 
ineffective for insurance and redistribution when households adjust their labor supply along the extensive margin. The divisibility of labor substantially increases the ability of the program in improving risk sharing and reducing inequality.

\section{Robustness Checks}

This section examines the robustness of the results in the previous section. First, following Alonso-Ortiz and Rogerson (2010), we consider larger labor hours $H=0.33$ and $\bar{h}=0.407$ under indivisible labor (I-H). Second, we set the process for idiosyncratic productivity to that used in Aiyagari and McGrattan (1998) for both indivisible and divisible labor: $\rho=0.60$ and $\sigma=0.24$ (I-IP and D-IP). The persistence is close to the lower bound of the persistence assumed in previous works, and the process for idiosyncratic productivity generates a much smaller dispersion of wages than it does in the benchmark case. For these two kinds of robustness checks, we reset the discount factor and the labor disutility so that the aftertax interest rate and aggregate labor hours match their targets. Table 2 summarizes these parameter values. Third, following Trabandt and Uhlig (2011), we analyze cases in which the levels of government consumption, government bonds, and net imports are fixed at those under the benchmark tax rate (I-LV and D-LV), instead of their ratios to output. These cases use the same parameter values as those in the benchmark case. ${ }^{15}$

Figure 8 displays the capital-output ratio and the consumption Gini. In all cases with indivisible labor, expanding the tax and transfer system is not effective in terms of reducing consumption uncertainty and inequality. Raising the consumption tax rate from the current rate of $5 \%$ increases the capital-output ratio, or aggregate savings, thereby reducing the interest rate. The dispersion of consumption across states and households is also largely

\footnotetext{
${ }^{15}$ We also change the relative risk aversion $\mu$ and the Frisch labor supply elasticity $\varphi$ under divisible labor, assuming that the momentary utility function for $\mu>0$ and $\mu \neq 1$ is

$$
u(c, h)=\frac{1}{1-\mu}\left\{c^{1-\mu}\left[1-\psi(1-\mu) h^{1+\frac{1}{\varphi}}\right]^{\mu}-1\right\},
$$

as in Trabandt and Uhlig (2011). We try $\mu=2.0$ and $\varphi=0.5$ and 2.0. Our main results did not change.
} 
insensitive to the scale of the government transfer program.

In contrast, for all cases with divisible labor, the consumption tax and transfer system is much more effective in terms of improving risk sharing and reducing inequality. The capital-output ratio decreases monotonically with the consumption tax rate, thereby raising the interest rate. The dispersion of consumption also decreases substantially.

Table 3 shows the welfare implications, listing the optimal consumption tax rate and the welfare gains from raising the tax rate from $5 \%$ to $35 \% .{ }^{16}$ The sum of the inequality and uncertainty gains is negative under indivisible labor and hence an increase in the tax and transfer program worsens welfare in terms of inequality and uncertainty. In contrast, under divisible labor, the sum of the inequality and uncertainty gains is always positive, suggesting that the transfer scheme works as insurance and redistribution.

The analysis in this section shows that our main results are robust to individual labor hours, the process for idiosyncratic productivity, and the way in which the other government policy variables are adjusted.

\section{Conclusion}

One rationale for a tax and transfer program is to enhance risk sharing against idiosyncratic earnings risk. We analyzed the insurance effect of a consumption tax and transfer system using a heterogeneous-agent, incomplete-market model with idiosyncratic wage risk and indivisible labor. We found that the transfer program is ineffective as insurance. Even when the program is expanded enormously by raising the consumption tax rate from the U.S. to the Danish rate, households face greater consumption uncertainty, causing aggregate savings to increase and the interest rate to fall. Consumption inequality is also largely unaffected. The transfer program is much more effective in reducing consumption uncertainty and inequality when labor is divisible.

\footnotetext{
${ }^{16}$ The optimal consumption tax rate $\tau_{c}$ is expressed as a percentage. The welfare gains $\left(\omega_{U}, \omega_{\text {lev }}, \omega_{\text {ine }}+\right.$ $\left.\omega_{\text {unc }}\right)$ are expressed as a percentage of the consumption at the $5 \%$ tax rate. Recall that the sum of the inequality and uncertainty gains is independent of how we determine the certainty-equivalent leisure.
} 
There are several directions for future research. First, it would be interesting to analyze lump-sum transfers and other fiscal policies in a model where labor supply responds through both intensive and extensive margins, such as the model recently developed by Chang, Kim, Kwon, and Rogerson (2014). A relevant extension is to use a two-earner model, such as that of Chang and Kim (2006). ${ }^{17}$ Second, the life-cycle implications as well as intergenerational risk sharing and redistribution should be examined using an overlapping generations model.

\section{References}

Aiyagari, S. R. (1994): "Uninsured Idiosyncratic Risk and Aggregate Saving," Quarterly Journal of Economics, 109(3), 659-684.

Aiyagari, S. R., and E. R. McGrattan (1998): "The Optimum Quantity of Debt," Journal of Monetary Economics, 42(3), 447-469.

Alonso-Ortiz, J., and R. Rogerson (2010): "Taxes, Transfers and Employment in an Incomplete Markets Model," Journal of Monetary Economics, 57(8), 949-958.

Chang, Y., And S.-B. Kim (2006): "From Individual to Aggregate Labor Supply: A Quantitative Analysis Based On A Heterogeneous Agent Macroeconomy," International Economic Review, 47(1), 1-27.

(2007): "Heterogeneity and Aggregation: Implications for Labor-Market Fluctuations," American Economic Review, 97(5), 1939-1956.

Chang, Y., S.-B. Kim, K. Kwon, and R. Rogerson (2014): "Individual and Aggregate Labor Supply in a Heterogeneous Agent Economy with Intensive and Extensive Margins," mimeo.

\footnotetext{
${ }^{17}$ Building on the work by Saez (2002), Kleven, Kreiner, and Saez (2009) and Immervoll, Kleven, Kreiner, and Verdelin (2011) analyze the optimal tax and transfer policy for couples.
} 
Cho, J.-O., And R. Rogerson (1988): "Family Labor Supply and Aggregate Fluctuations," Journal of Monetary Economics, 21(2-3), 233-245.

Coleman, W. J. I. (2000): "Welfare and Optimum Dynamic Taxation of Consumption and Income," Journal of Public Economics, 76(1), 1-39.

Correia, I. (2010): "Consumption Taxes and Redistribution," American Economic Review, 100(4), 1673-1694.

Feve, P., J. Matheron, and J.-G. Sahuc (2013): "The Laffer Curve in an IncompleteMarket Economy," mimeo.

Flodén, M. (2001): "The Effectiveness of Government Debt and Transfers as Insurance," Journal of Monetary Economics, 48(1), 81-108.

FlodÉn, M., AND J. Lindé (2001): "Idiosyncratic Risk in the United States and Sweden: Is There a Role for Government Insurance?," Review of Economic Dynamics, 4(2), 406-437.

Gunji, H., And K. Miyazaki (2011): "Estimates of Average Marginal Tax Rates on Factor Incomes in Japan," Journal of the Japanese and International Economics, 25(2), 81-106.

Hansen, G. D. (1985): "Indivisible Labor and the Business Cycle," Journal of Monetary Economics, 16(3), 309-327.

Hayashi, F., and E. C. Prescott (2002): "The 1990s in Japan: A Lost Decade," Review of Economic Dynamics, 5(1), 206-235.

Immervold, H., H. J. Kleven, C. T. Kreiner, and N. Verdelin (2011): "Optimal Tax and Transfer Programs for Couples with Extensive Labor," Journal of Public Economics, 95(11-12), 1485-1500.

KitaO, S. (2011): "Macroeconomic and Redistributional Effects of Consumption Taxes in the USA," Japanese Economic Review, 62(1), 63-81. 
Kleven, H. J., C. T. Kreiner, and E. Saez (2009): "The Optimal Income Taxation of Couples," Econometrica, 77(2), 537-560.

Krusell, P., T. Mukoyama, R. Rogerson, and A. Şahin (2010): "Aggregate Labor Market Outcomes: The Roles of Choice and Chance," Quantitative Economics, 1(1), 97127.

_ (2011): "A Three State Model of Worker Flows in General Equilibrium," Journal of Economic Theory, 146(3), 1107-1133.

Lise, J., N. Sudo, M. Suzuki, K. Yamada, and T. Yamada (2014): "Wage, Income and Consumption Inequality in Japan, 1981-2008: From Boom to Lost Decades," Review of Economic Dynamics, 17(4), 582-612.

Nishiyama, S., and K. Smetters (2005): "Consumption Taxes and Economic Efficiency with Idiosyncratic Wage Shocks," Journal of Political Economy, 113(5), 1088-1115.

Nutahara, K. (2015): "Laffer Curves in Japan," Journal of the Japanese and International Economies, 36, 56-72.

Pijonn-Mas, J. (2006): "Precautionary Savings or Working Longer Hours," Review of Economic Dynamics, 9(2), 326-352.

Rogerson, R. (1988): "Indivisible Labor, Lotteries and Equilibrium," Journal of Monetary Economics, 21(1), 3-16.

SAez, E. (2002): "Optimal Income Transfer Programs: Intensive versus Extensive Labor Supply Responses," Quarterly Journal of Economics, 117(3), 1039-1073.

Sugo, T., And K. Ueda (2008): "Estimating a Dynamic Stochastic General Equilibrium Model for Japan," Journal of the Japanese and International Economics, 22(4), 476-502.

Tauchen, G. (1986): "Finite State Markov-Chain Approximations to Univariate and Vector Autoregressions," Economics Letters, 20(2), 177-181. 
Trabandt, M., and H. Uhlig (2011): "The Laffer Curve Revisited," Journal of Monetary Economics, 58(4), 305-327.

Ventura, G. (1999): "Flat Tax Reform: A Quantitative Exploration," Journal of Economic Dynamics and Control, 23(9-10), 1425-1458. 


\begin{tabular}{|c|c|c|}
\hline Symbol & Meaning & Value \\
\hline$\beta$ & Discount factor & 0.9696 \\
\hline$g$ & Growth rate & 0.02 \\
\hline$\delta$ & Capital depreciation rate & 0.07 \\
\hline$\theta$ & Capital share & 0.38 \\
\hline $\bar{h}$ & Individual hours worked & 0.33 \\
\hline$\varphi$ & Frisch labor supply elasticity & 1.0 \\
\hline$\psi$ & Labor disutility & 6.09 \\
\hline$H$ & Aggregate hours worked & 0.25 \\
\hline$\rho$ & Persistence in idiosyncratic productivity & 0.94 \\
\hline$\sigma_{\varepsilon}$ & Volatility of idiosyncratic productivity shocks & 0.205 \\
\hline$\tau_{c}$ & Consumption tax rate & 0.05 \\
\hline$\tau_{n}$ & Labor income tax rate & 0.28 \\
\hline$\tau_{k}$ & Capital income tax rate & 0.36 \\
\hline$\tilde{G}$ & Government consumption-output ratio & 0.18 \\
\hline$\tilde{M}$ & Net import-output ratio & 0.04 \\
\hline$\tilde{B}$ & Debt-output ratio & 0.63 \\
\hline
\end{tabular}

Table 1: Baseline parameter values. 


\begin{tabular}{llll}
\hline \hline & $\begin{array}{l}\text { indivisible } \\
\text { large labor } \\
(\mathrm{I}-\mathrm{H})\end{array}$ & $\begin{array}{l}\text { indivisible } \\
\text { less persistent risk } \\
(\mathrm{I}-\mathrm{IP})\end{array}$ & $\begin{array}{l}\text { less persistent risk } \\
(\mathrm{D}-\mathrm{IP})\end{array}$ \\
\hline$\beta$ & 0.9714 & 0.9791 & 0.9794 \\
$\psi$ & 4.26 & 6.18 & 5.22 \\
$H$ & 0.33 & 0.25 & 0.25 \\
$\bar{h}$ & 0.407 & 0.333 & $\mathrm{NA}$ \\
$\rho$ & 0.94 & 0.60 & 0.60 \\
$\sigma_{\varepsilon}$ & 0.205 & 0.24 & 0.24 \\
\hline \hline
\end{tabular}

Table 2: Parameter values for robustness checks. 


\begin{tabular}{lllll}
\hline \hline & Optimal $\tau_{c}$ & $\omega_{U}$ & $\omega_{\text {lev }}$ & $\omega_{\text {ine }}+\omega_{\text {unc }}$ \\
\hline $\mathrm{D}$ & 10 & -1.0 & -4.3 & 3.4 \\
$\mathrm{D}-\mathrm{LV}$ & 0 & -3.7 & -6.5 & 3.0 \\
$\mathrm{D}-\mathrm{IP}$ & 0 & -4.5 & -5.1 & 0.7 \\
$\mathrm{I}$ & 10 & -1.2 & 3.2 & -4.2 \\
$\mathrm{I}-\mathrm{LV}$ & 5 & -3.7 & 0.0 & -3.6 \\
$\mathrm{I}-\mathrm{IP}$ & 0 & -4.8 & -1.6 & -3.3 \\
$\mathrm{I}-\mathrm{H}$ & 10 & -2.5 & 5.2 & -7.1 \\
\hline \hline
\end{tabular}

Table 3: Welfare. 


\section{Transfers/Output}

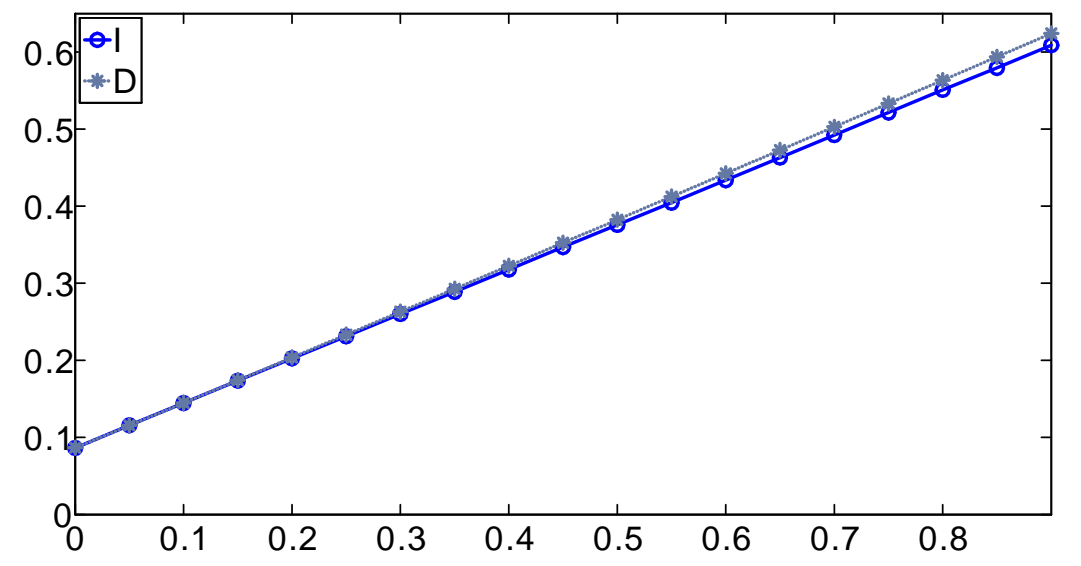

Figure 1: Transfers-output ratio. I: baseline indivisible labor. D: baseline divisible labor. Horizontal axis: consumption tax rate $\tau_{c}$. 

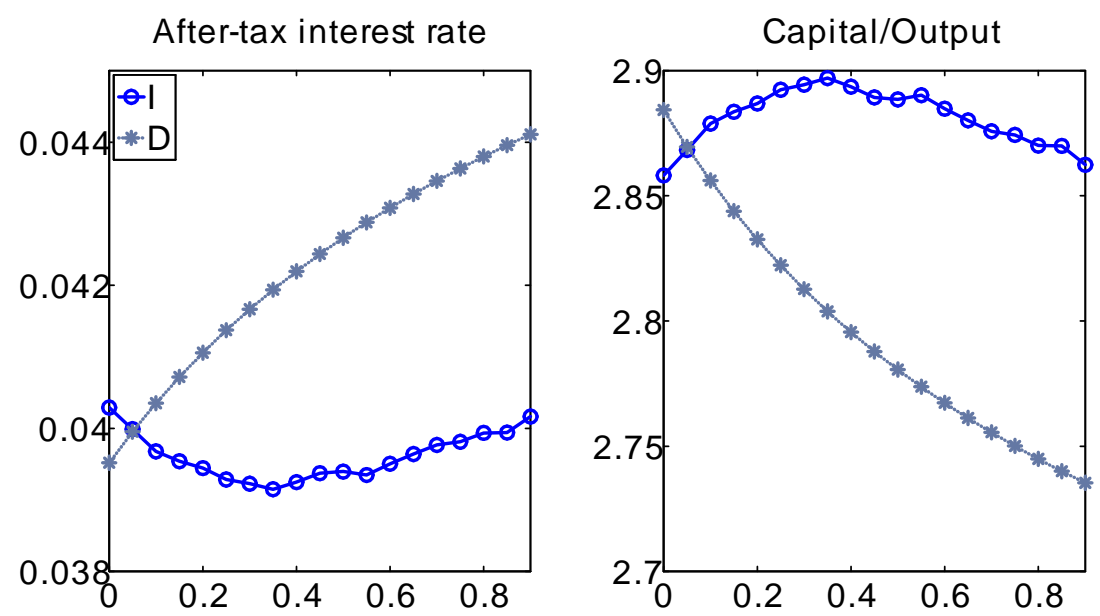

Figure 2: Interest rate and capital-output ratio. I: baseline indivisible labor. D: baseline divisible labor. Horizontal axis: consumption tax rate $\tau_{c}$. 

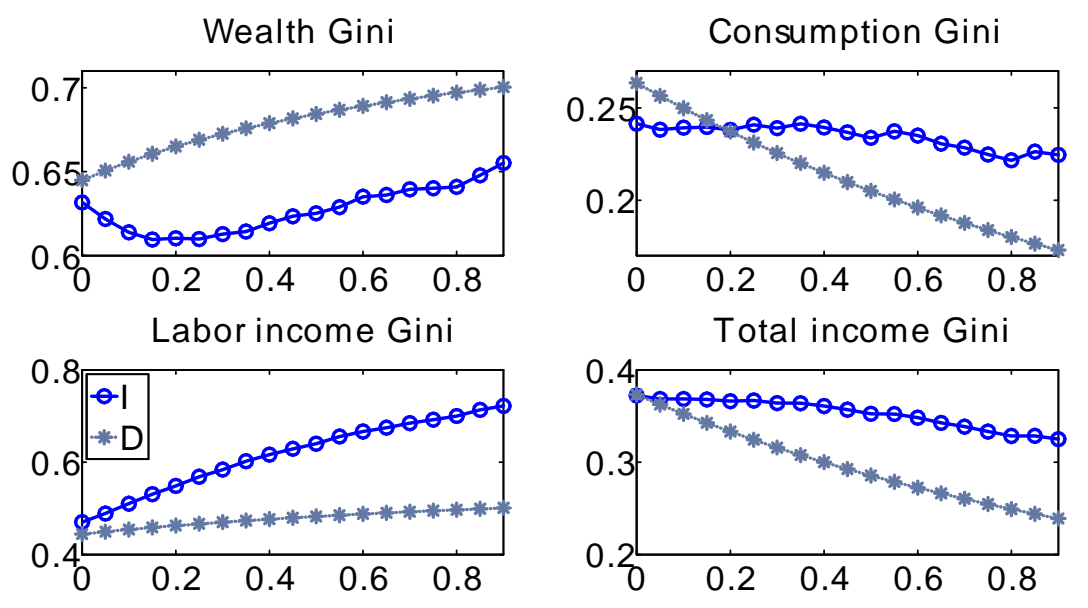

Figure 3: Inequality. I: baseline indivisible labor. D: baseline divisible labor. Horizontal axis: consumption tax rate $\tau_{c}$. 

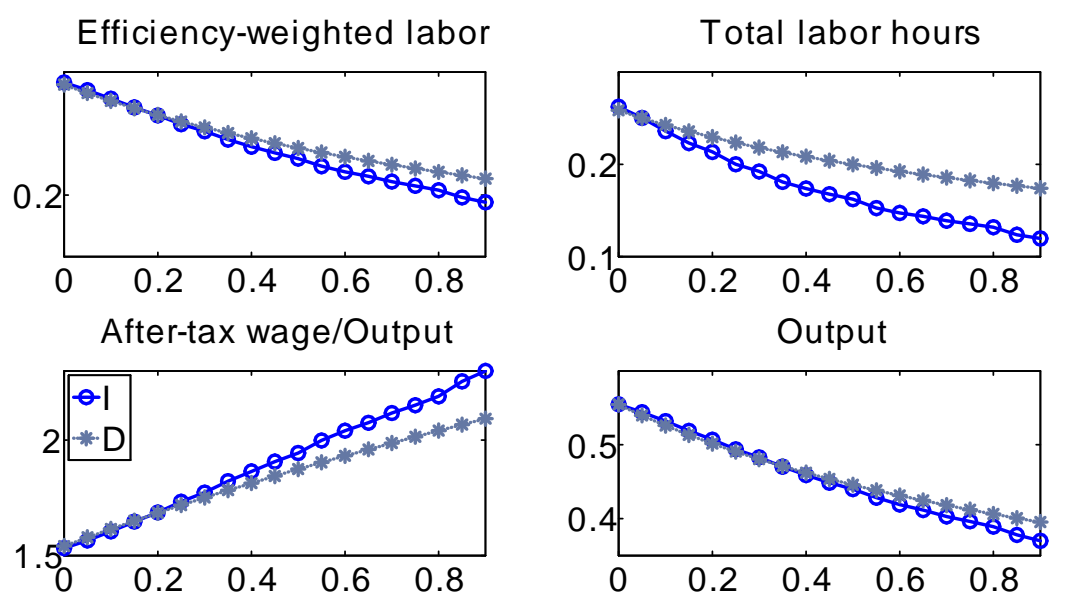

Figure 4: Aggregate labor input, wage rate, and output. I: baseline indivisible labor. D: baseline divisible labor. Horizontal axis: consumption tax rate $\tau_{c}$. 

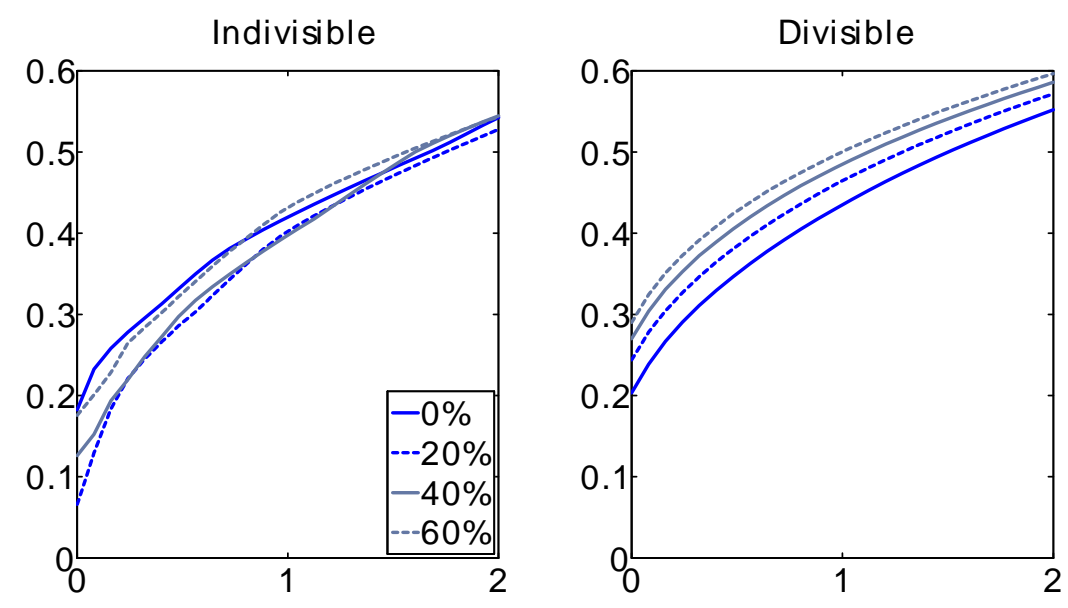

Figure 5: Cumulative asset distribution for consumption tax rates of $0 \%, 20 \%, 40 \%$, and 60\%. Horizontal axis: wealth. 

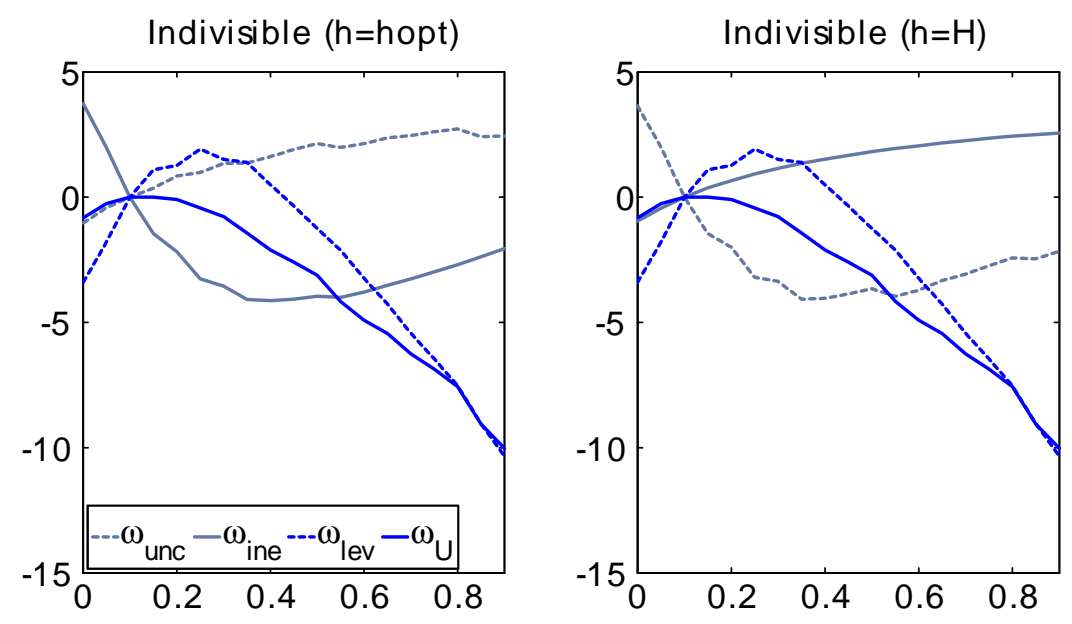

Figure 6: Welfare under indivisible labor. The horizontal axis shows the welfare gain, which is expressed as a percentage of consumption at the initial tax rate (5\%). We determine the certainty-equivalent leisure in two ways: setting hours to the current level ( $h=h o p t)$ and setting it to the economy average $(h=H)$. Horizontal axis: consumption tax rate $\tau_{c}$. 

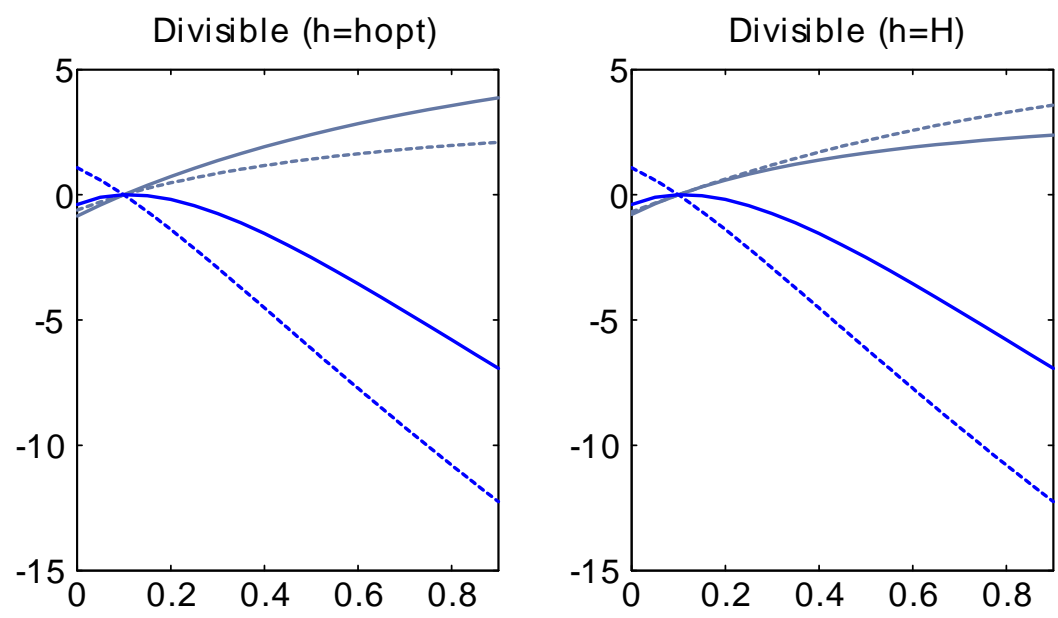

Figure 7: Welfare under divisible labor. The horizontal axis shows the welfare gain, which is expressed as a percentage of consumption at the initial tax rate (5\%). We determine the certainty-equivalent leisure in two ways: setting hours to the current level $(h=h o p t)$ and setting it to the economy average $(h=H)$. Horizontal axis: consumption tax rate $\tau_{c}$. 

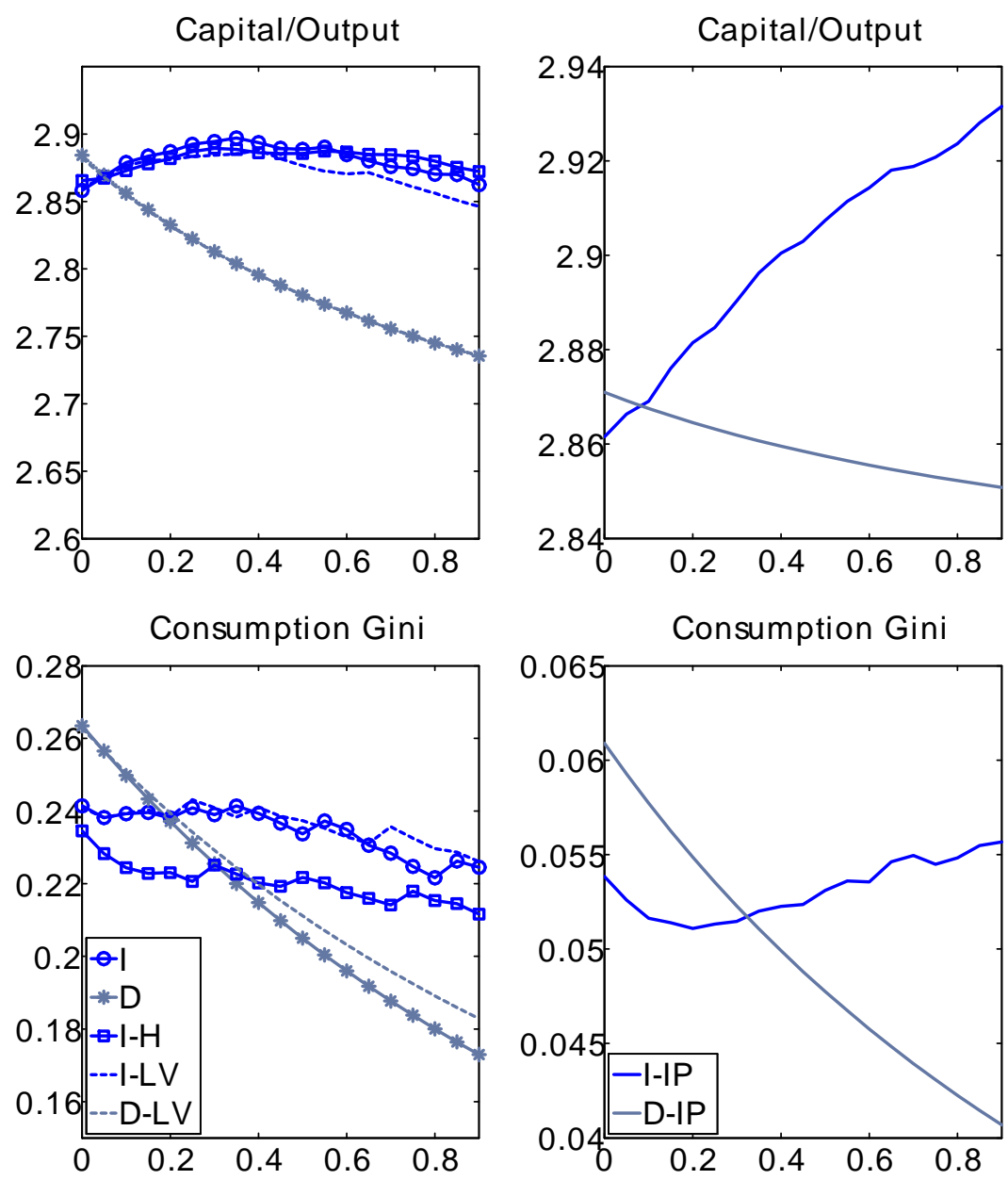

Figure 8: Capital-output ratio and consumption Gini. I: baseline indivisible labor. D: baseline divisible labor. I-H: I with large hours. I (D)-IP: I (D) with less persistent productivity. I (D)-LV: I (D) with fixed levels of government consumption, bonds, and net imports. Horizontal axis: consumption tax rate $\tau_{c}$. 


\section{Appendix A: Labor Income Taxes}

We analyze the transfer program financed through labor income taxes using our benchmark indivisible and divisible labor models. We change the labor income tax rate from $0 \%$ to $90 \%$ in $5 \%$ increments and adjust transfers endogenously such that the government budget constraint (11) holds. Unlike consumption taxes, there is a peak in the Laffer curve for labor income taxes. The highest transfer-output ratio is lower than that attained in the program based on consumption taxes, as shown in Figure 9. In fact, the transfer-output ratio also has a peak under indivisible labor.

Nonetheless, the labor income tax and transfer system improves risk sharing under both indivisible and divisible labor. As shown in Figure 10, when the labor income tax rate rises, the capital-output ratio and the dispersion of consumption both decrease monotonically. These results are in line with those of previous studies, such as Flodén (2001) (divisible labor) and Alonso-Ortiz and Rogerson (2010) (indivisible labor). In the case of labor income taxes, a hike in the tax rate decreases the after-tax wage rate, mitigating an increase in labor income volatility. With larger transfers, the uncertainty and inequality in total income decrease substantially. Hence, expanding the tax and transfer system reduces consumption uncertainty and inequality. 


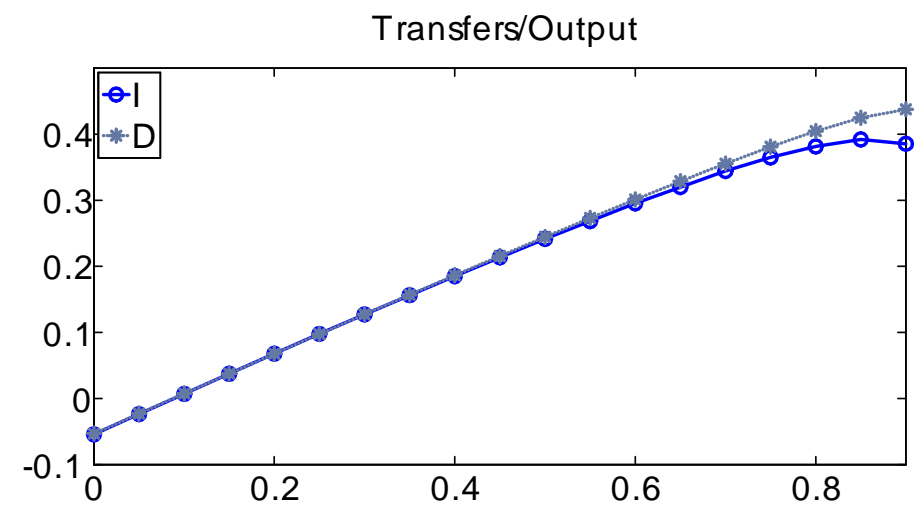

Figure 9: Transfers-output ratio for labor income taxes. I: baseline indivisible labor. D: baseline divisible labor. Horizontal axis: labor income tax rate $\tau_{n}$. 

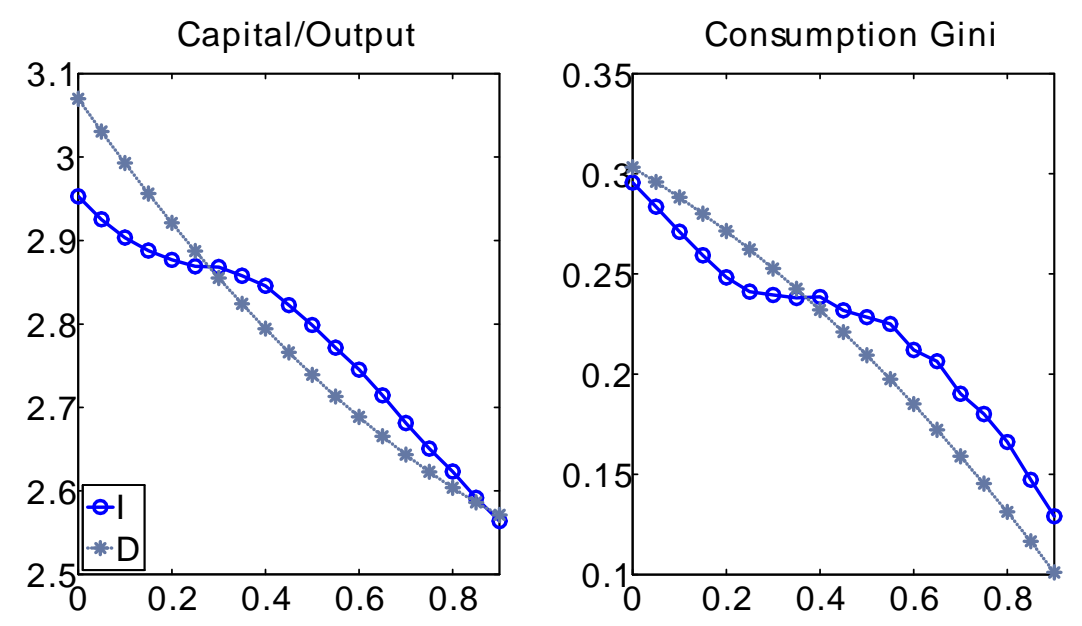

Figure 10: Capital-output ratio and consumption Gini for labor income taxes. I: baseline indivisible labor. D: baseline divisible labor. Horizontal axis: labor income tax rate $\tau_{n}$. 


\section{Appendix B: Consumption Taxes in Japan}

We calibrate our model to the Japanese economy and analyze the effect of changing consumption taxes and transfers on risk sharing. The exercise can be seen as an additional robustness check.

\section{B.1 Parameter Values}

Table 4 lists the parameter values. These are taken mostly from Nutahara (2015), who determines those values based on previous studies, such as Hayashi and Prescott (2002), Sugo and Ueda (2008), and Gunji and Miyazaki (2011). The capital depreciation rate $\delta$ is 0.06 and the capital share $\theta$ is 0.37 .

Hours worked when employed $\bar{h}$ are 0.333 , as in the U.S. case. The Frisch labor supply elasticity is 1.0. The disutility of labor $\psi$ is adjusted such that the total hours worked $H$ is 0.212 , as in Nutahara (2015).

The stochastic process for idiosyncratic productivity is typically estimated using panel data of individual wages. However, such panel data is limited in Japan. Hence, we use the U.S. values: $\rho=0.94$ and $\sigma_{\epsilon}=0.205$. The calibrated model generates the wealth Gini, similar to the empirical value documented in Lise, Sudo, Suzuki, Yamada, and Yamada (2014).

The capital income tax rate $\tau_{k}$ is 0.52 , while the labor income tax rate $\tau_{n}$ is 0.29 . The

share of government consumption in GDP $\tilde{G}$ is 0.154 . The ratio of net imports to GDP $\tilde{M}$ is -0.016 . The ratio of government debt to GDP $\tilde{B}$ is 1.11 .

Note that two departures from Nutahara (2015) are the benchmark consumption tax rate $\tau_{c}$ and the growth rate of real GDP $g$. We set their values to the average values between 1995 and 2013: $\tau_{c}=0.05$ and $g=0.01$.

Lastly, we choose the discount factor $\beta$ so that the after-tax rate of the return on savings $\left(1-\tau_{k}\right) r$ is $2.06 \%$, following Nutahara (2015). The result is $\beta=0.9802$. 


\section{B.2 Results}

We conduct the same exercise for the U.S. economy (see Figure 11). As in the United States, the consumption tax and transfer program is ineffective in terms of insurance and redistribution. Expanding the transfer program from the current level slightly increases the capital-output ratio (or aggregate savings), thereby reducing the interest rate. The dispersion of consumption also increases. The consumption tax and transfer program is effective for risk sharing and reducing inequality when labor is divisible, as in the United States. ${ }^{18}$ Expanding the program reduces aggregate savings, raising the interest rate. Consumption inequality also decreases substantially.

\footnotetext{
${ }^{18}$ For the divisible labor version of our model, we set $\beta=0.9829$ and $\psi=6.75$, matching the targets of the interest rate and aggregate hours worked.
} 


\begin{tabular}{lll}
\hline \hline Symbol & Meaning & Value \\
\hline$\beta$ & Discount factor & 0.9802 \\
$g$ & Growth rate & 0.01 \\
$\delta$ & Capital depreciation rate & 0.06 \\
$\theta$ & Capital share & 0.37 \\
$\bar{h}$ & Individual hours worked & 0.333 \\
$\varphi$ & Frisch labor supply elasticity & 1.0 \\
$\psi$ & Labor disutility & 7.31 \\
$H$ & Aggregate hours worked & 0.212 \\
$\rho$ & Persistence in idiosyncratic productivity & 0.94 \\
$\sigma_{\varepsilon}$ & Volatility of idiosyncratic productivity shocks & 0.205 \\
$\tau_{c}$ & Consumption tax rate & 0.05 \\
$\tau_{n}$ & Labor income tax rate & 0.29 \\
$\tau_{k}$ & Capital income tax rate & 0.52 \\
$\tilde{G}$ & Government consumption-output ratio & 0.154 \\
$\tilde{M}$ & Net import-output ratio & -0.016 \\
\hline \hline & Debt-output ratio & 1.11 \\
\hline & & \\
\hline & & \\
\hline
\end{tabular}

Table 4: Parameter values for Japanese economy. 

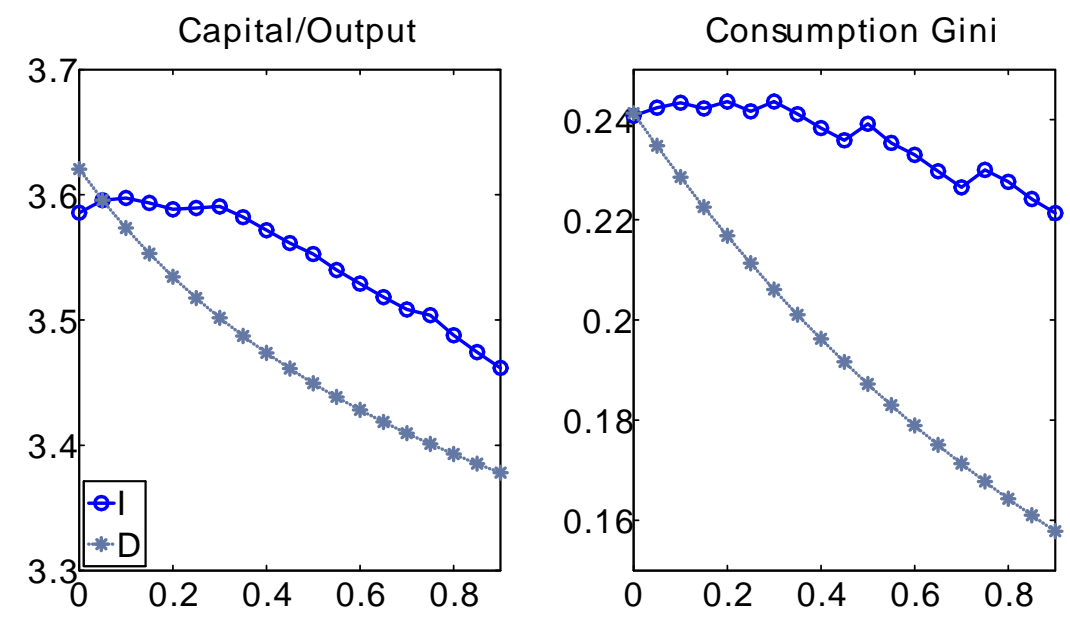

Figure 11: Capital-output ratio and consumption Gini for Japan. I: indivisible labor. D: divisible labor. Horizontal axis: consumption tax rate $\tau_{c}$. 


\section{Appendix C: Numerical method}

Here, we explain the method used to solve the household optimization problem and to find the stationary household distribution.

1. Discretize the idiosyncratic state $(\tilde{a}, e)$. Set 10 log-spaced points over $[0,20]$ for assets $\tilde{a}$. For idiosyncratic productivity $e$, set 17 evenly spaced points over $\left[-3 \sigma_{\varepsilon} / \sqrt{1-\rho^{2}}\right.$, $\left.3 \sigma_{\varepsilon} / \sqrt{1-\rho^{2}}\right]$, and compute the transition matrix using the method of Tauchen (1986).

2. Set a guess for the after-tax interest rate $\left(1-\tau_{k}\right) r$ and aggregate labor input $N$. The wage rate $\tilde{w}$ is given by $(5)$. Then, the transfer-output ratio $\tilde{T}$ is given by the government budget constraint of (11), with the aggregate resource constraint, $1=$ $\tilde{C}+\tilde{G}+\delta \tilde{K}$, where the capital-output ratio $\tilde{K}$ is computed from (4).

3. Given $\left(\tau_{c}, \tau_{n}, \tau_{k}, r, \tilde{w}, \tilde{T}\right)$, solve the household optimization problem and obtain the beginning-of-period value function $V(\tilde{a}, e)$.

(a) Set a guess for the beginning-of-period value function $V^{0}(\tilde{a}, e)$.

(b) Solve the consumption-saving problem for each employment choice, as in (8) and (9). Use the cubic spline interpolation to approximate the conditional expectation at $\tilde{a}^{\prime}$ off their grid points. If $V^{E}(\tilde{a}, e) \geq V^{N}(\tilde{a}, e)$, then households with $\tilde{a}$ and $e$ choose to work. Otherwise, they do not work. Set $V(\tilde{a}, e)=$ $\max \left\{V^{E}(\tilde{a}, e), V^{N}(\tilde{a}, e)\right\}$.

(c) If $V(\tilde{a}, e)$ becomes sufficiently close to $V^{0}(\tilde{a}, e)$, then proceed to the next step. Otherwise, update the value function to $V^{0}(\tilde{a}, e)=V(\tilde{a}, e)$ and return to (b).

4. Compute the stationary distribution of households $\Gamma(\tilde{a}, e)$.

(a) Choose points used to approximate the distribution. Use 250 log-spaced points over $[0,20]$ for $\tilde{a}$, and the points chosen in Step 1 for $e$. 
(b) Using $V(\tilde{a}, e)$ obtained in Step 3 (c), solve the household problem this time for $250 \times 17$ pairs of $(\tilde{a}, e)$, and determine their optimal asset holding $\tilde{a}^{\prime}(\tilde{a}, e)$ and hours worked $h(\tilde{a}, e)$.

(c) Suppose $\tilde{a}_{m} \leq \tilde{a}^{\prime}(\tilde{a}, e)<\tilde{a}_{m+1}$, where $\tilde{a}_{m}$ and $\tilde{a}_{m+1}$ are two sequential asset points. Starting from an initial guess, keep updating the distribution until the distribution converges as follows: Households with $(\tilde{a}, e)$ move to $\left(\tilde{a}_{m}, e^{\prime}\right)$, with probability $\omega \pi_{e}\left(e^{\prime} \mid e\right)$, and to $\left(\tilde{a}_{m+1}, e^{\prime}\right)$, with probability $(1-\omega) \pi_{e}\left(e^{\prime} \mid e\right)$, where $\omega=\left(\tilde{a}_{m+1}-\tilde{a}^{\prime}\right) /\left(\tilde{a}_{m+1}-\tilde{a}_{m}\right)$. The result is the stationary household distribution $\Gamma(\tilde{a}, e)$.

5. Check whether the asset and labor markets clear: $\tilde{K}=\int a d \Gamma-\tilde{B}$ and $N=\int e h(\tilde{a}, e) d \Gamma$. If the market-clearing conditions are nearly satisfied, then stop. Otherwise, set different guesses for $\left(1-\tau_{k}\right) r$ and $N$ and repeat Steps 2-5. 